\title{
Conflitos socioambientais e limites da gestão compartilhada em Unidade de Conservação na zona costeira amazônica
}

\author{
Otávio do Canto \\ Universidade Federal do Pará - Belém - Pará - Brasil \\ ORCID: https://orcid.org/0000-0002-6209-9646 \\ Mário Vasconcellos Sobrinho \\ Universidade Federal do Pará e Universidade da Amazônia - Belém - Pará - \\ Brasil \\ ORCID: https://orcid.org/0000-0001-6489-219X
}

Ana Maria de A. Vasconcellos

Universidade da Amazônia - Belém - Pará - Brasil

ORCID: https://orcid.org/0000-0002-7594-3578

Luciana Rodrigues Ferreira

Universidade da Amazônia - Belém - Pará - Brasil

ORCID: https://orcid.org/0000-0002-7043-0765

Ana lalis Baretta

Universidade Federal do Pará - Belém - Pará - Brasil

ORCID: https://orcid.org/0000-0003-4480-197X

\section{Resumo}

O artigo discute a emergência de conflitos socioambientais e os limites da gestão compartilhada de territórios na zona costeira amazônica brasileira. De forma particular, o artigo debate os conflitos socioambientais e os limites da gestão compartilhada em 3 (três) Unidades de Conservação (UC) na zona costeira do estado do Pará, precisamente: RESEX Mãe Grande de Curuçá, RESEX Mestre Lucindo e APA Algodoal-Maiandeua. Em termos teóricos, alicerça-se nos conceitos de conflito socioambiental e gestão compartilhada, este último dentro do campo analítico de gestão social. Metodologicamente, trata-se de um estudo baseado na pesquisa-ação apoiado em técnicas de observação participante e entrevistas semiestruturadas. Para análise dos dados foi utilizado o método de análise de redes. O artigo demonstra a existência de quatro categorias de conflitos: (1) os relacionados a empreendimentos econômicos, (2) os conexos à degradação do ambiente e dos recursos naturais, (3) os originados nas práticas econômicas e ocupacionais locais e (4) aqueles resultantes das implicações legais e sociais. As diferentes categorias e tipos de conflito demonstram a complexidade que os conselhos gestores enfrentam no processo de 
gestão compartilhada. A pesquisa demonstra que a gestão compartilhada tem limitações, entretanto é, até então, o melhor modelo para gestão de UC. Conclui-se que a gestão compartilhada é processo e prática e que se potencializa na medida em que os atores envolvidos ganham experiência e promovem de forma crescente diálogo e o interesse bem compreendido a partir da participação social.

Palavras-chave: Conflitos socioambientais. Gestão compartilhada. Unidades de Conservação. Zona Costeira

\section{Socio-environmental conflicts and limits of shared management in a Conservation Unit in the Amazon coastal zone}

\section{Abstract}

The paper discusses the emergence of socio-environmental conflicts and the limits of shared territory management in Brazilian Amazonian coastal zone. Particularly, the article debates socio-environmental conflicts and the limits of shared management in 3 (three) Conservation Units (UC) in the coastal zone of Pará state, precisely: RESEX Mãe Grande de Curuçá, RESEX Mestre Lucindo and APA Algodoal- Maiandeua. Theoretically, the paper is based on the concepts of socio-environmental conflict and shared management, the latter within the analytical field of social management. Methodologically, it is a study based on action research supported by method of participant observation and techniques of semistructured interviews. For data examination, it was used the method of network analysis. The article demonstrates the existence of four categories of conflicts: (1) first, conflicts related to economic enterprises, (2) second, those related to the degradation of the environment and natural resources, (3) third, conflicts that arise from local economic and occupational practices and (4) fourth, those resulting of legal and social inferences. The different categories and types of conflict demonstrate the complexity that management councils face in the shared management process. The research shows that shared management has limitations, however it is, so far, the best pattern for UC management. The article concludes that shared management is a process and practice and that it becomes more potent as the actors involved gain experience and increasingly promote dialogue and well-understood interest based on social participation.

Keywords: Socio-environmental conflicts. Shared management. Conservation Units. Coastal zone..

\section{Conflictos socioambientales y límites de la gestión compartida en Unidades de Conservación en la zona costera amazónica}

\section{Resumen}

Compartida de la tierra en la zona costera amazónica brasileña. En particular, el artículo analiza los conflictos socioambientales y los límites de la gestión compartida en tres (3) Unidades de Conservación (UC) en la zona costera del estado de Pará, precisamente: RESEX Mãe Grande de Curuçá, RESEX Mestre Lucindo y APA Algodoal-Maiandeua. En términos teóricos, el artículo se basa en los conceptos de conflicto socioambiental y gestión compartida, este último dentro del campo analítico de la gestión social. Metodológicamente, se trata de un estudio basado en la investigación de acción basada en técnicas de observación de participantes y entrevistas semiestructuradas. Para el análisis de datos, se utilizó el método de análisis de red. El artículo demuestra la existencia de cuatro categorías de conflictos: 1) los relacionados con las empresas económicas, 2) los relacionados con la degradación del medio ambiente y los recursos naturales, 3) los originados en las prácticas económicas y ocupacionales locales y 4) los resultantes de las implicaciones jurídicas y sociales. Las diferentes categorías y tipos de conflicto demuestran la complejidad a la que se enfrentan los consejos de administración en el proceso de gestión compartida. La investigación demuestra que la administración compartida tiene 
limitaciones, pero es, hasta entonces, el mejor modelo para la gestión de la UC. El artículo concluye que la gestión compartida es un proceso y una práctica y que se potencia a medida que los actores involucrados adquieren experiencia y promueven el diálogo y el interés bien entendido de la participación social.

Palabras clave: Conflictos Socioambientales; Administración Compartida; Unidades de Conservación; Zona Costera.

\section{Introdução}

O objeto desta investigação se colocou no debate sobre os conflitos socioambientais que tem emergido em 3 (três) Unidades de Conservação (UC) RESEX Mãe Grande de Curuçá, RESEX Mestre Lucindo e APA Algodoal-Maiandeua, e os limites do uso do método de gestão compartilhada enquanto modelo de gestão dos territórios na zona costeira das Amazônias brasileiras, particularmente na zona costeira do estado do Pará.

Toma-se como referência principal de análise os conselhos gestores das UC (LE TOURNEAU; CANTO, 2019). Esses têm o caráter deliberativo e, portanto, de grande responsabilidade na manutenção das UC, seja em termos de conservação da biodiversidade e belezas naturais, seja em termos de assegurar direitos aos modos de vida de seus moradores e usuários para manutenção de seus territórios abrigos (CANTO, 2016) e reprodução social. Após séculos de hegemonia de uma visão simplificada do conceito de Amazônia, uma visão de pluralidade passou a se impor e o termo Amazônias (LE TOURNEAU; CANTO, 2019) tem assumido protagonismo alicerçado no entendimento da existência de diferentes ecossistemas e da sociodiversidade. Entendemos, assim, as UC, tanto no interior como na zona costeira, como representações dessas Amazônias.

Inicialmente, gestão compartilhada pode ser entendida como "estratégia e gestão formalizada que conecta comunidades locais e governos" (ARMITAGE; BERKES; DOUBLEDAY, 2007, p. 2). Dentre as estratégias utilizadas para essa conexão está a participação das comunidades nos espaços públicos de gestão, entendendo-a como uma forma de promover uma gestão democrática. Isto está instituído em leis e regramentos para gestão de UC.

Um dos aspectos da maior importância da gestão compartilhada das UC é o compartilhamento do sistema de decisões por meio dos conselhos deliberativos. As decisões, por princípio, devem ser tomadas em conjunto pelos usuários, instituições locais e poder público. Desta maneira, um instrumento fundamental para analisar as decisões coletivas são os Planos de Manejo. Esses foram, então, nosso segundo objeto de análise para entender os conflitos socioambientais resultantes dos diferentes interesses de apropriação e uso dos recursos naturais disponíveis, e os limites da gestão compartilhada.

Neste contexto, a questão que dimensionou a pesquisa foi: quais os limites da gestão compartilhada para superação dos conflitos socioambientais emergentes na zona costeira das Amazônias brasileiras, particularmente na zona costeira do estado do Pará?

O artigo está estruturado em 7 seções incluindo esta introdução e as considerações conclusivas. A segunda seção discute de forma resumida os conceitos de conflito socioambiental e gestão compartilhada. Entende-se que 
ambos conceitos merecem mais profundos debates. Entretanto, busca-se com essa seção apenas apresentar os entendimentos conceituais para o que se propõe o debate no artigo. A terceira seção apresenta o significado de Unidades de Conservação à luz da legislação que a estabelece e demonstra seus elementos constitutivos que são objetos de análise: participação, conselhos e os planos de manejo. A quarta seção apresenta os encaminhamentos metodológicos da pesquisa. Na quinta seção, apresenta-se as UC na zona costeira do estado do Pará e especificamente a APA e RESEX estudadas. A sexta seção é que adentra especificamente nos conflitos socioambientais identificados no trabalho de campo e reflete sobre limites e potencialidades da gestão compartilhada.

\section{Conflito socioambiental e gestão compartilhada: um breve entendimento conceitual}

Existem duas principais correntes de interpretação relativas ao debate sobre conflito. A primeira que considera o conflito como anomalia, uma externalidade que se manifesta no interior dos grupos sociais. Esta interpretação é encontrada na visão durkheimiana que sugere que os grupos sociais são harmônicos e equilibrados. Nesta perspectiva, a harmonia e o equilíbrio fazem parte da objetividade do grupo social, por isso qualquer conflito que se manifeste no seio do grupo deve apresentar suas justificativas fora do grupo social onde o mesmo se manifesta. Assim, o conflito é gerado por externalidades e deve ser eliminado para restabelecer o estado "normal" de harmonia e equilíbrio no grupo social afetado.

A segunda corrente de interpretação compreende o conflito como parte integrante do processo social que produz o grupo no seu território. Assim sendo, o conflito não é algo para ser resolvido, mas parte integrante do cotidiano do grupo social, podendo, em alguns momentos, se intensificar e gerar mudanças substanciais no sistema organizacional e territorial do grupo. Porém, em outras circunstâncias pode se manter latente, exigindo apenas a mediação por parte dos seus membros de forma a evitar que se transforme em convulsão social. Assim sendo, o conflito não é passível de ser resolvido, ele é parte integrante da vida social e estimulador das mudanças necessárias a cada momento da história, sendo entendido pelo grupo como importante para a manutenção do grupo e do seu território.

Estudos relativos aos conflitos socioambientais têm recebido especial atenção no âmbito da Ecologia Política (CANTO, 2016), cujo foco tem sido a justiça social em função do uso dos recursos naturais, e da gestão do desenvolvimento (VASCONCELLOS SOBRINHO et al., 2018), cujo foco é a cooperação para o desenvolvimento territorial por via do uso adequado dos recursos territoriais, incluindo os recursos naturais. Sob uma perspectiva ou outra, os conflitos sociais são entendidos como decorrentes dos embates entre diferentes sujeitos e grupos sociais que disputam a apropriação e uso dos recursos.

Dado esse entendimento, nas amazônias, caracterizadas por uma imensa socio-bio-diversidade dos territórios, ocorrem conflitos de múltiplas formas que decorrem do controle e uso de lagos, rios, igarapés, florestas, caça, madeira, minério, etc. Assim, pode-se afirmar que os conflitos socioambientais estão diretamente conectados à dimensão territorial, surgindo a partir das diferentes 
formas de apropriação dos conhecimentos, das técnicas e dos recursos naturais pelos diversos sujeitos sociais que se articulam de acordo com os interesses e conveniências, que são históricas. (CANTO, 2016, p.82-83).

Nesta vertente, os conflitos socioambientais ocorrem à medida que os indivíduos e grupos sociais disputam o uso do território, no processo de apropriação dos recursos naturais (LITTLE, 2002). Assim, território e conflitos fazem parte do mesmo processo e se concretizam no espaço de vivência ou no 'espaço vivido' (CANTO, 2016). Como dizem Canto e Almeida (2008, p.93), “o território é resultado da dinâmica da vida e deve ser assimilado por meio da análise dos processos de territorialização que os grupos sociais empreendem dia-a-dia, na luta para existirem". Com efeito, pode-se afirmar, então, que os conflitos socioambientais emergem dentro dos processos de territorialização que tem de forma imbricada e indissociada a natureza e a sociedade, pois são os humanos, frutos da natureza que transformarem essa mesma natureza, transformam a si mesmos e, nesse sentido, criam o meio ambiente de modo ininterrupto. (CANTO; ALMEIDA, 2008, p.93).

Para esta pesquisa, parte-se do princípio de que não há território senão como resultado do trabalho, pois ele transforma a natureza e impõe, a cada momento da história, trabalho sobre o trabalho preexistente. Essa dinâmica recria a natureza cada vez mais distante da sua forma original, e assim sendo, natureza e sociedade tornam-se parte de uma mesma realidade inseparável. O território, nesta perspectiva, é campo de possibilidades e rompe com a visão que coloca a natureza como externalidade, algo separado da condição humana. Desse modo a gestão compartilhada do território é muito importante em relação os conflitos socioambientais em decorrência das disputas pelos recursos naturais.

O conceito de gestão compartilhada ainda se apresenta muito difuso e entrecruzado com outros conceitos, tais como cogestão, gestão coletiva, gestão participativa, ajuda-mútua, regime de produção compartilhada, ações coletivas, gestão social e governança. Todavia, em todos os conceitos congêneres, a participação dos atores na tomada de decisão é o elemento comum. A gestão compartilhada pautada pela participação de todos àqueles que serão afetados pela tomada de decisão tende a inverter o processo vertical tradicional predominante que caracteriza as organizações e os colegiados. Embora a participação per si não possa promover a gestão compartilhada, sem ela não há como estabelecer esse modelo de gestão. A gestão compartilhada neste âmbito é a gestão realizada em conjunto por vários atores que se reúnem para gerir projetos, processos, organizações e territórios dentro do estabelecimento de um objetivo comum.

No debate de gestão compartilhada de territórios há pelo menos duas vertentes predominantes. A primeira centrada na sociedade (society-centred approach). Nesta perspectiva, os atores do território de auto organizam para gerir um território de propriedade comum, seja em função da sua tradicionalidade (FERREIRA; VASCONCELLOS SOBRINHO, 2016), seja em função na necessidade premente de organizar o território para uso e apropriação dos recursos naturais.

A segunda vertente é centrada nas instituições (Institutional-centred approach). Nesta vertente o modelo de gestão compartilhada é determinado por instituições, leis e regras, em geral capitaneadas pelo Estado. Para esta perspectiva, a gestão compartilhada é baseada na existência de uma arena formal (CARLSSON; 
BERKES, 2003) para diálogo e cooperação, tais como conselhos, fóruns, colegiados, dentre outros.

Em ambas vertentes a gestão compartilhada se apresenta como um processo complexo uma vez que os atores envolvidos não são unos, mas partes distintas, com interesses e demandas distintos a despeito do objetivo comum que se quer alcançar com o modelo de gestão. No Institutional-centred approach há, ainda, o desafio de superar o distanciamento entre os desejos e necessidades das comunidades locais e objetivos pré-estabelecidos por agentes do Estado.

No contexto da gestão compartilhada que prevê a participação de atores na tomada de decisão, o campo teórico e prático da gestão social (CANÇADO; PEREIRA; TENÓRIO, 2015) apresenta uma interessante contribuição.

Tenório (2007) emoldura o conceito de gestão social alicerçado no entendimento de cidadania deliberativa. Com efeito, a gestão social coloca a sociedade protagonista no processo de tomada de decisão como forma de promover a emancipação dos sujeitos e/ou grupos sociais. Para que a cidadania deliberativa se manifeste é necessário, segundo o autor, a existência de processos de discussão orientados pelos princípios de inclusão, pluralismo, igualdade participativa, autonomia e bem comum (TENÓRIO, 2007; CANÇADO; PEREIRA; TENÓRIO, 2015), dentro de esferas púbicas (CANÇADO; PEREIRA; TENÓRIO, 2015). Essas seriam os espaços de intermediação entre sociedade e Estado (e mercado) sendo, assim, a cidadania deliberativa como processo participativo de deliberação baseado essencialmente no entendimento entre os atores (e não no convencimento ou negociação) (TENÓRIO, 2007; CANÇADO; PEREIRA; TENÓRIO, 2015). Nesse sentido, pelo menos 3 características são fundamentais para 0 exercício da gestão social dentro da esfera pública: participação, dialogicidade e interesse bem compreendido.

Para efeito deste artigo, a gestão compartilhada no contexto da gestão social deve ser entendida como um modus operandi de gestão do território que envolve participação; diálogo; tomada de decisão coletiva, sem correção, a partir do interesse bem compreendido; transparência; e emancipação. Adiciona-se a essas características, o entendimento e manutenção do conflito como motor das transformações históricas, necessárias para assegurar a sobrevivência dos grupos sociais em seus territórios.

Sumarizando as concepções acima apresentadas sobre conflitos socioambientais e gestão compartilhada, pode-se afirmar que ambos serão sempre partes de uma mesma realidade na gestão territorial, sobretudo dento da vertente do Institutional-centred approach a qual as Unidades de Conservação estão envolvidas.

\section{Unidades de Conservação: participação, conselhos e planos de manejo como elementos constitutivos}

A Lei 9.985/2000 que instituiu o Sistema Nacional de Unidades de Conservação (SNUC) trouxe critérios e normas para a criação, implantação e gestão das unidades de conservação (UC). Uma UC, segundo a lei, é um 
espaço territorial e seus recursos ambientais, incluindo as águas jurisdicionais, com características naturais relevantes, legalmente instituído pelo Poder Público, com objetivos de conservação e limites definidos, sob regime especial de administração, ao qual se aplicam garantias adequadas de proteção (BRASIL, 2000, p. 1).

Com efeito, existem dois tipos de unidades de conservação determinados por essa legislação: (1) as UC de proteção integral e (2) as UC de uso sustentável. As UC surgem como instrumento de preservação e conservação ambiental, tendo por finalidade assegurar uso racional dos recursos naturais e resguardar os saberes e culturas das populações que nelas vivem e trabalham (CANTO; VASCONCELLOS SOBRINHO; VASCONCELLOS; ABREU; MENEZES; REBELO, 2017).

A criação de uma UC, normalmente, ocorre a partir de demanda da sociedade para proteção de determinada área ou para assegurar o uso sustentável dos recursos naturais das populações que nelas vivem e trabalham. A gestão das UC deve ocorrer de forma que resulte no desenvolvimento das coletividades locais. Destaque-se que o SNUC, além de estabelecer critérios para criação e gestão das UCs, institui a participação social como fundamental na administração delas.

A materialização de uma UC decorre de ato do poder público (federal, estadual ou municipal), após a realização de estudos técnicos e consulta pública que permitam identificar a localização, a dimensão e os limites mais adequados para a unidade. Segundo a Lei 9.985/2000, as UCs são constituídas com objetivos de conservação e seus limites devem ser definidos sob regime especial de administração. De acordo com artigo 30, "as unidades de conservação podem ser geridas por organizações da sociedade civil de interesse público com objetivos afins aos da unidade, mediante instrumento a ser firmado com o órgão responsável por sua gestão" (BRASIL, 2000, p. 4)

Para o processo de gestão, o SNUC determina que cada UC estabeleça um Conselho Gestor, seja para auxiliar na sua gestão, seja para assegurar a integração das coletividades locais. Os mesmos podem ser estabelecidos na modalidade consultiva ou deliberativa.

Esses conselhos, seja consultivo ou deliberativo, devem assumir como princípio a participação social, configurando, assim, uma estrutura para a gestão compartilhada entre representantes da sociedade civil e agentes do Estado. De fato, segundo o SNUC, os conselhos devem ter representação de órgãos públicos, tanto da área ambiental como de áreas afins, da sociedade civil, sobretudo da população residente e do entorno, população local, povos indígenas, proprietários de imóveis no interior da UC, trabalhadores e setor privado atuantes na região, comunidade científica e organizações não-governamentais com atuação comprovada na região.

Ainda que os conselhos não se constituam como espaços que garantam a efetiva participação e o pleno exercício democrático, os mesmos tem sido considerado como o melhor modelo para gestão de UC dentro do contexto nacional (LOUREIRO; AZAZIEL; FRANCA; 2003).

O principal instrumento de gestão a ser usado nas UCs quer na esfera nacional, quer na estadual, é o plano de manejo. Este deve ser elaborado a partir de um diagnóstico socioambiental da região, especificando as condições físicas e sociais. 
O plano de manejo deve considerar os objetivos gerais da UC e estabelecer normas de uso dos recursos do território, especificando, inclusive, as restrições e ações a serem desenvolvidas e, evidentemente, o próprio manejo dos recursos naturais. No documento deve haver medidas de prevenção à superexploração dos recursos naturais e, também, ações que permitam a promoção da integração da UC com as comunidades que a compõem ou a cercam.

Em princípio, o plano de manejo deve ser discutido e aprovado pelos usuários ou suas representações nas várias instâncias de tomada de decisão (reuniões comunitárias e do conselho) como forma de diminuir os conflitos entre os diferentes atores do território (usuários, órgãos públicos, instituições da sociedade civil).

Assim, contar com a participação social no conselho e na elaboração do plano de manejo implica no compartilhamento de gestão e responsabilidades entre todos aqueles que serão diretamente atingidos pelas limitações decorrentes da implementação da UC. Parte-se do entendimento que a participação social oferece maior efetividade às medidas protetivas a partir da possibilidade de maior compreensão por parte dos atores envolvidos por via do diálogo inerente à atuação daquele. No mais, o conselho e o plano de manejo permitirão à gestão acesso à cultura local e saberes tradicionais a partir do diálogo dos sujeitos envolvidos.

Um sistema mais rígido de gestão, sem compartilhamento, poderia aumentar e facilitar a gestão propriamente dita, assim como a tomada de decisão. Todavia, ao mesmo tempo, correr-se-ia o risco de ignorar interesses dos sujeitos do processo e acabar, assim, sendo um risco ao próprio sistema. Daí a própria Constituição Federal, em seu art. $225^{1}$, conferir à coletividade o dever de preservação do meio ambiente, sendo a gestão compartilhada um meio de se alcançar tal objetivo. Desta forma, foi conferido à coletividade o direito à preservação do meio ambiente, mas, da mesma forma, o dever de fazê-lo. Deste modo, a Constituição estabeleceu a democracia participativa para a gestão ambiental, conferindo responsabilidade à coletividade. (MENDONÇA, TALBOT, 2014).

\section{Metodologia}

Metodologicamente, a pesquisa foi baseada na pesquisa-ação, que segundo Thiollent (2002), é uma linha de pesquisa que tem a orientação e função de possibilitar a resolução de problemas, assim como integrar-se a objetivos de transformação em relação ao objeto pesquisado, caracterizada por ações de observação, descrição, avaliação e planejamento de intervenção orientada e participação direta.

Para Thiollent (2002) e Macke (2006), a definição de pesquisa-ação reflete sua complexidade de aplicação por sua empiria e grau elevado de participatividade e cooperatividade, fato que orientou o estudo qualitativo do trabalho de campo.

\footnotetext{
${ }^{1}$ Art. 225. Todos têm direito ao meio ambiente ecologicamente equilibrado, bem de uso comum do povo e essencial à sadia qualidade de vida, impondo-se ao Poder Público e à coletividade o dever de defendê-lo e preservá-lo para as presentes e futuras gerações.
} 
Em relação aos procedimentos metodológicos, utilizou-se as técnicas de observação participante e entrevistas semiestruturadas.

\subsection{Observação participante}

A técnica foi orientada a partir do diário de campo como membro dos conselhos gestores das 3 (três) UC estudadas e que, junto com outros pesquisadores, vivenciaram a construção de:

(a) elaboração de uma cartografia participativa, como contribuição à preparação do plano gestor da RESEX Mestre Lucindo; (

b) redação de atas de reuniões dos conselhos gestores da RESEX Mãe Grande de Curuçá, RESEX Mestre Lucindo e da APA Algodoal-Maiandeua e, ainda,

(c) construção do perfil socioeconômico das Unidades Familiares Beneficiárias (UFB) da RESEX Mestre Lucindo.

\subsection{Entrevistas}

Foram realizadas 56 entrevistas que seguiram quatro eixos fundamentais:

(1) Identificação dos conflitos socioambientais existentes na UC;

(2) das instituições as quais os membros dos conselhos recorrem para obter informação quando da existência de conflitos socioambientais;

(3) do grau de importância das três principais instituições apontadas por cada conselheiro entrevistado (definiu-se que a gradação de importância seria representada por 01 como a mais importante e 03 a menos importante); e,

(4) dos limites advindos da gestão compartilhada para solução dos conflitos. Os dados coletados permitiram a construção das teias de relações que os conselhos possuem para equacionar questões de conflitos.

Em relação ao recorte temporal da pesquisa-ação e a aplicação das técnicas de entrevistas e observação participante ocorreram por via de várias incursões às UC entre 2016 e 2018.

Para análise de dados utilizamos o método de análise de redes com o uso do software UCINET 6.664 e adaptamos o modelo analítico de categorização e origem de conflitos relacionados ao meio socioespacial ambiental apresentado por Honda (2018). Neste modelo analítico categoriza-se o conflito em 4 tipos: o primeiro tipo relacionado a empreendimentos econômicos, o segundo pertinente à degradação do ambiente e dos recursos naturais, o terceiro originado de práticas econômicas e ocupacionais e o último resultante de implicações legais e sociais.

\section{As UC na zona costeira do estado do Pará}

Com base no Zoneamento Ecológico-Econômico (ZEE) do Pará, a zona costeira paraense compreende uma área de $83.342,17$ quilômetros quadrados. A zona costeira abriga 22 unidades de conservação, sendo 20 de uso sustentável e 2 de proteção integral. As mesmas criam uma espécie de cinturão verde dominado por diversos ecossistemas, com destaque para os manguezais. De forma mais específica, são 14 Reservas Extrativistas (RESEXs), 5 Áreas de Proteção Ambiental (APAs), 1 Reserva de Desenvolvimento Sustentável (RDS), 1 Refúgio de Vida Silvestre (REVIS) e 1 Parque Estadual (PES). 
A pesquisa escolheu 3 (três) unidades para acompanhamento e análises, são elas, da esquerda para a direita da figura 1: RESEX Mãe Grande de Curuçá (localizada no município de Curuçá), RESEX Mestre Lucindo (localizada no município de Marapanim) e APA Algodoal-Maiandeua (localizada no município de Maracanã). A área dessas três unidades de conservação compreende 659,04 quilômetros quadrados.

Figura 1 - Unidades de Conservação da Zona Costeira do Estado do Pará

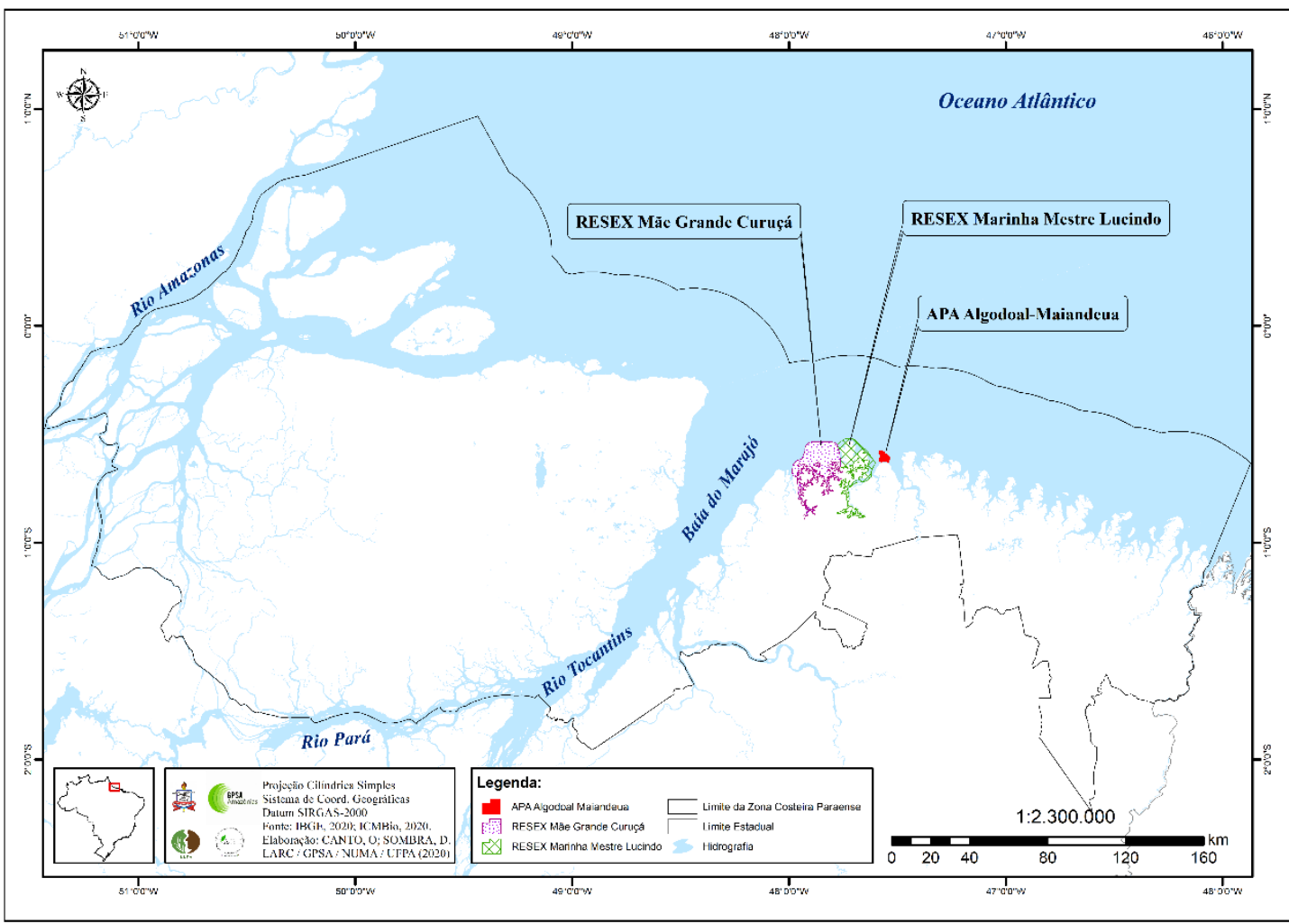

Elaboração: LARC, 2020.

a) RESEX Mãe Grande de Curuçá

A RESEX Mãe Grande de Curuçá envolve uma área de 37.062 hectares e é habitada por 52 comunidades. A sua gestão é compartilhada por meio de um conselho gestor composto por 27 membros e seus suplentes. No conselho estão representantes das esferas governamentais, de organizações não-governamentais, de sociedade civil organizada e de usuários da unidade de conservação.

b) RESEX “Mestre Lucindo"

A RESEX Mestre Lucindo ocupa uma área de 26.464,88 hectares e é habitada por 29 comunidades. Sua organização social e comunitária está estruturada em oito polos (cada um deles possui um comitê gestor); associações comunitárias e a "Associação Mãe", denominada de Associação dos Usuários da Reserva Extrativista Marinha "Mestre Lucindo" (AUREMLUC). O conselho gestor é conformado por 23 instituições, entretanto somente 18 delas tem frequência regular desde o início de seu funcionamento em 20 de abril de 2018. 
c) APA Algodoal-Maiandeua

A Área de Proteção Ambiental Algodoal-Maiandeua (APA AlgodoalMaiandeua) foi criada em 1990 e envolve uma área de 2.378 hectares, sendo 385 hectares na ilha de Algodoal e 1.993 hectares na ilha de Maiandeua (LOBATO, 1999). Não obstante serem duas ilhas, as comunidades locais consideram-na como uma única ilha e a denominam de Maiandeua. Desde 980 a ilha de Maiandeua tem sido considerada um dos principais polos turísticos do estado do Pará. Sua beleza resulta da combinação entre praias, restingas, mangues, furos e 4 quatro povoados. Algodoal, Camboinha, Fortalezinha e Mocooca. conselho gestor é de caráter deliberativo e é formado por 22 instituições das esferas federal, estadual, municipal e comunitária.

AS RESEX e APA escolhidas expressam recortes territoriais significativos da grande complexidade dos ecossistemas que compõem a zona costeira paraense. Essa complexidade determina múltiplos usos dos recursos naturais disponíveis pelas comunidades locais a partir dos seus específicos modos de vida.

Dessa forma, nessas unidades espaciais os territórios são produzidos pelos modos de vida das populações e suas relações com interesses de diversos sujeitos e de instituições internas e externas, as quais são afetadas e ganham novas dinâmicas a partir das restrições impostas pela criação das UC. Vale destacar que as comunidades locais constroem relações que vão do lugar ao mundo, na velocidade da disponibilidade de instrumentos técnicos cujo acesso é possível, condições que Ihes impõem conflitos de diversas ordens, transformando o modo de vida a cada momento da sua história.

Canto; Vasconcellos Sobrinho; Vasconcellos; Abreu; Menezes; Rebelo (2017) demonstram a existência de conflitos socioambientais muito fortes na zona costeira paraense decorrentes das disputas entre os diversos grupos sociais pelo uso dos recursos naturais. Tais conflitos se manifestam em razão das disputas pela apropriação e uso das matas ciliares que acompanham os igarapés e rios que se dirigem para o mar, as praias e dunas, os mangues e restingas, além das demais áreas privilegiadas e de grande interesse imobiliário, dentre outros. Esses conflitos foram identificados nas 3 unidades de conservação aqui apresentadas.

De fato, é muito comum se verificar nas comunidades que convivem e se relacionam dentro das UC disputas pela apropriação dos recursos naturais e dos meios de produção com a finalidade de garantir seu sustento, o que resulta em verdadeiro conflito socioambiental. Desta forma, a eficácia da gestão compartilhada está relacionada, dentre outros fatores à possibilidade de compreensão dos conflitos, sobretudo socioambientais.

\section{Conflitos socioambientais e limites da gestão compartilhada}

Como expresso por Little (2002) e Canto e Almeida (2008), os conflitos socioambientais ocorrem na medida em que os indivíduos e grupos sociais disputam o uso do território no processo de apropriação dos recursos naturais, ocorrendo, assim, dentro dos processos de territorialização. Os conflitos socioambientais se fazem presente em função dos divergentes interesses entre os atores que se relacionam com o território. Situações como essa evidenciam a complexidade do sistema de gestão compartilhada. A própria criação de uma UC, por si só, gera 
conflitos em decorrência das restrições de uso dos recursos naturais que são implementadas a partir de sua instituição.

Nas 3 (três) UC pesquisadas foi comum a identificação de grupos sociais disputando espaço e poder nos conselhos gestores no processo de apropriação e uso dos recursos naturais, ainda que por meio de regras institucionais. Este tipo de conflito, predominantemente de ordem político-ideológica, aflora quando há a presença de atores de mercado (ou com perspectiva de mercadocêntrica) e de usuários da UC que visam fundamentalmente a reprodução social. No caso da APA Algodoal-Maiandeua, disputas de espaço e poder dentro do conselho gestor entre membros representantes de hotéis e pousadas com representantes do IDEFLOR-bio em função do uso irregular do solo, que por exemplo, mostram perspectivas diferenciadas para gestão da UC. No caso da RESEX Mãe Grande de Curuçá, perspectiva econômico-ideológica entre atores do governo municipal e outros grupos sociais do conselho de gestor sobre a possibilidade de implantação de um porto de transbordo de minério em área da UC leva ao conflito sobre o uso do território. Nesta mesma linha de raciocínio, identificou-se conflitos relacionados à privatização de pequenos portos ao longo dos cursos d'água RESEX Mãe Grande de Curuçá. No caso da RESEX Mestre Lucindo, por ser uma UC nova e ainda em processo de implementação, dentre os conflitos de ordem de disputas de poder está à falta de fluxos de informação intra UC e conselho gestor, assim como entre os representantes dos polos que compõem o quadro gestor juntamente com a Associação dos Usuários da Reserva Extrativista Marinha Mestre Lucindo (AUREMLUC) e o ICMBIO. Ainda que se veja como conflitos de ordem política, e sob uma tensão entre interesse individual/grupo e interesse coletivo/comunidade, na realidade todos esses conflitos estão estritamente vinculados à questões socioambientais e territoriais.

De fato, na APA Algodoal-Maiandeua, o trabalho de campo identificou que os conflitos mais presentes estão em torno do uso e ocupação do solo, usos geralmente econômicos, empreendimentos turísticos, construções ilegais e extração de recursos naturais. Na APA Algodoal Maiandeua, por ser um polo turístico, tem se apresentado novos atores sociais, proprietários de residências de veraneio, que vem intervindo no espaço e que estão transformando a estrutura e organização física do território. Como parte desse processo, há, ainda, atividades de retirada os recursos naturais, (areia, pedra, barro, exploração madeireira) para fins de construção civil em escala bem mais acelerada nos últimos 10 anos. Este processo se dá pela retirada de recursos naturais tanto por parte das novas residências, quanto, principalmente, pelos moradores nativos da ilha (HONDA, 2018). Isto tem ocasionado, na faixa de praia na vila de Algodoal, várias modificações no processo natural de variações da maré. Segundo Mascarenhas e Vidal (2013), tem ocorrido maior acumulação na preamar e predominância de erosão durante o refluxo de baixa-mar, ou seja, o nível de sedimentos da areia tem variado significativamente pelo movimento do mar. Isto ocorre porque há interferência humana na remoção de sedimentos arenosos na faixa de praia provocando desnível no solo e aceleração da erosão (MASCARENHAS; VIDAL, 2013). Segundo Plano de Manejo da unidade é proibido a extração de areia e bens comuns naturais, pois pode trazer vários tipos de consequências como a aceleração da erosão do solo, alteração no meio biofísico do solo e entre outros desequilíbrios ambientais. 
Na RESEX Mãe Grande de Curuçá, os conflitos mais citados pelos entrevistados estão relacionados à pesca e catação de caranguejo sedo que, no segundo caso, se caracteriza pela forma desordenada de captura do crustáceo e da sobreexploração do mesmo. Furtado (2004), define a territorialidade na pesca como o "espaço construído e disputado por diversas categorias de pescadores": pescadores de rede, pescadores de curral, pescadores de bote, de grandes embarcações, pescadores de fora, pescadores de dentro, dentre outros. Essas diversas categorias de pescadores, no caso da RESEX Mãe Grande de Curuçá, são submetidas às dinâmicas das políticas públicas, do que está estabelecido no plano de manejo, e por outras externalidades que afetam as relações de grupo, do grupo com o meio, as concepções de mudanças que modificam os meios tradicionais de acesso ao recursos, que acabam por levar ao uso de métodos predatórios de pesca. Neste caso, pode-se afirmar a existência de pescadores versus pescadores e conflitos interinstitucionais de rebatimentos socioambientais.

É comum em todas 3 UC conflitos de outras ordens e que apareceram em menor expressão durante as pesquisas de campo, mas que precisam ser considerados quando analisarmos seus impactos no meio ambiente e território, dentre esses podemos destacar: desmatamento e queimadas; degradação dos mangues; uso irregular das orlas e de gestão dos resíduos sólidos, sobretudo de plásticos que não se decompõem facilmente na natureza e ausência de fiscalização por parte dos órgãos do Estado.

Quadro 1 - Categorização e origem de conflitos relacionados ao meio socioespacial ambiental identificados nas UC

\begin{tabular}{|c|c|c|}
\hline Conflitos & Concepção do Conflito & Evidências \\
\hline $\begin{array}{l}\text { Conflitos relacionados à } \\
\text { empreendimentos } \\
\text { econômicos }\end{array}$ & $\begin{array}{l}\text { Conflitos que podem causar } \\
\text { impactos na estrutura física da UC e } \\
\text { no modo tradicional de se viver no } \\
\text { local }\end{array}$ & $\begin{array}{l}\text { - Construção de porto de Transbordo } \\
\text { - Construção de pequenos portos } \\
\text { - Construção de hotéis e pousadas }\end{array}$ \\
\hline $\begin{array}{l}\text { Conflitos relacionados à } \\
\text { degradação do } \\
\text { ambiente e dos recursos } \\
\text { naturais }\end{array}$ & $\begin{array}{l}\text { Conflitos originados da forma como } \\
\text { os recursos naturais são explorados } \\
\text { e os descartes realizados }\end{array}$ & $\begin{array}{l}\text { - Desmatamento } \\
\text { - Queimadas } \\
\text { - Retirada de areia, pedra, barro } \\
\text { - Exploração madeireira } \\
\text { - Descarte e acúmulo de resíduos }\end{array}$ \\
\hline $\begin{array}{c}\text { Conflitos originados nas } \\
\text { práticas econômicas e } \\
\text { ocupacionais }\end{array}$ & $\begin{array}{l}\text { Conflitos que degradam } \\
\text { irreversivelmente o meio ambiente } \\
\text { em função do ganho econômico }\end{array}$ & $\begin{array}{l}\text { - Sobrepesca } \\
\text { - Catação de caranguejos } \\
\text { - Construções irregulares }\end{array}$ \\
\hline $\begin{array}{c}\text { Conflitos resultantes } \\
\text { das implicações legais e } \\
\text { sociais }\end{array}$ & $\begin{array}{l}\text { Conflitos resultantes de questões } \\
\text { de ordem legais e institucionais }\end{array}$ & $\begin{array}{l}\text { - Falta de regularização fundiária } \\
\text { - Desobediência ao plano de manejo } \\
\text { - Ausência de fiscalização } \\
\text { - Baixo fluxo de informações } \\
\text { - Indefinição de competências entre } \\
\text { órgãos governamentais estadual e } \\
\text { federal } \\
\text { - Educação ambiental insatisfatória }\end{array}$ \\
\hline
\end{tabular}

Fonte: HONDA, 2018. Reelaboração dos autores.

Ponto positivo ao reconhecimento dos conflitos é que esses poderão levar ao fortalecimento das ações voltadas à gestão, com formação de estruturas de 
governança local. No caso de conflitos com grupos sociais externos a UC levam à coesão interna e fortalecimento de alianças. Nesse caso, os conflitos podes funcionar como vetor de gestão da UC, delineando as ações a serem adotadas para aumentar a efetividade e fortalecer objetivos da UC. No caso de conflitos entre os grupos sociais que fazem parte da UC, esses necessitam de mediação por parte do conselho gestor com apoio, em geral, de legislação e de representações externas à UC que podem auxiliar os grupos locais entenderem o origem e os pontos nevrálgicos de cada conflito e as possiblidades de superação por via da gestão compartilhada.

Dentro dessa ideia de mediação dos conflitos socioambientais como forma de minimizar as disputas pelo uso dos recursos naturais e a necessidade de fortalecer a gestão compartilhada como possibilidade de empoderamento social da UC como um todo, traçamos a constituição das redes de relações ${ }^{2}$ estabelecidas entre os membros dos conselhos gestores das 3 UC e, também, entre os conselheiros e instituições que tenham ou não representação no conselho gestor.

$\mathrm{Na}$ figura 2 observa-se, de modo sistemático, as relações dos entrevistados que representam as organizações do conselho gestor da RESEX Mãe Grande de Curuçá. A partir desta figura, foram analisados o nível de densidade e o grau de centralidade da rede.

A figura demonstra que os maiores fluxos de relações e diálogos entre os entrevistados perpassam em maior frequência pelo Instituto Chico Mendes de Conservação da Biodiversidade (ICMBIO), Associação dos Usuários da Reserva Extrativista Mãe Grande de Curuçá (AUREMAG) e Associação Comunitária (ASS.COM.), com 14, 13 e 12 citações respectivamente. Em seguida, com frequência média, tem-se a Colônia dos Pescadores Z-5 (C-Z5), com 5 citações. As demais entidades obtiveram frequência baixa, dentre essas a Prefeitura Municipal de Curuçá (PMC) e o próprio Conselho Gestor da Reserva Extrativista Mãe Grande de Curuçá (CGRMGC).

\footnotetext{
${ }^{2}$ Para organizar as respostas obtidas por meio de cada entrevista, utilizou-se o programa UCINET 6.664. Primeiramente produziu-se uma tabela simétrica (em software Excel) de relacionamento entre os entrevistados e entidades, onde o número de entrevistados(as) é o mesmo de entidades. Em alguns casos ocorreram agrupamentos de organizações. Em seguida fez-se a interface com o programa UCINET, definindo o número 1 (um) para a relação entre cada entrevistado(a)/entidade ou o (zero) para quando não há relação. Para facilitar o entendimento de como se expressa graficamente a rede de relacionamento entre entrevistados(as)/entidades citadas, utilizou-se a ferramenta NETDRAW 2.166, gerando a rede de relacionamento de fluxos. O nível de densidade mostra o valor em porcentagem da densidade da rede, isto é, demonstra se a rede apresenta uma alta ou baixa conectividade, sendo a medida expressa em porcentagem do coeficiente entre $O$ número das Relações Existentes (RE) com as Relações Possíveis (RP), dada pela seguinte relação: $D=$ $R E / R P \times 100.0$ cálculo das relações possíveis é obtido da seguinte forma: $1[R P=N T N \times(N T N-1)]$.
} 
Figura 2 - Rede de relações entre os conselheiros para diálogo e soluções de conflitos socioambientais - RESEX Mãe Grande de Curuçá

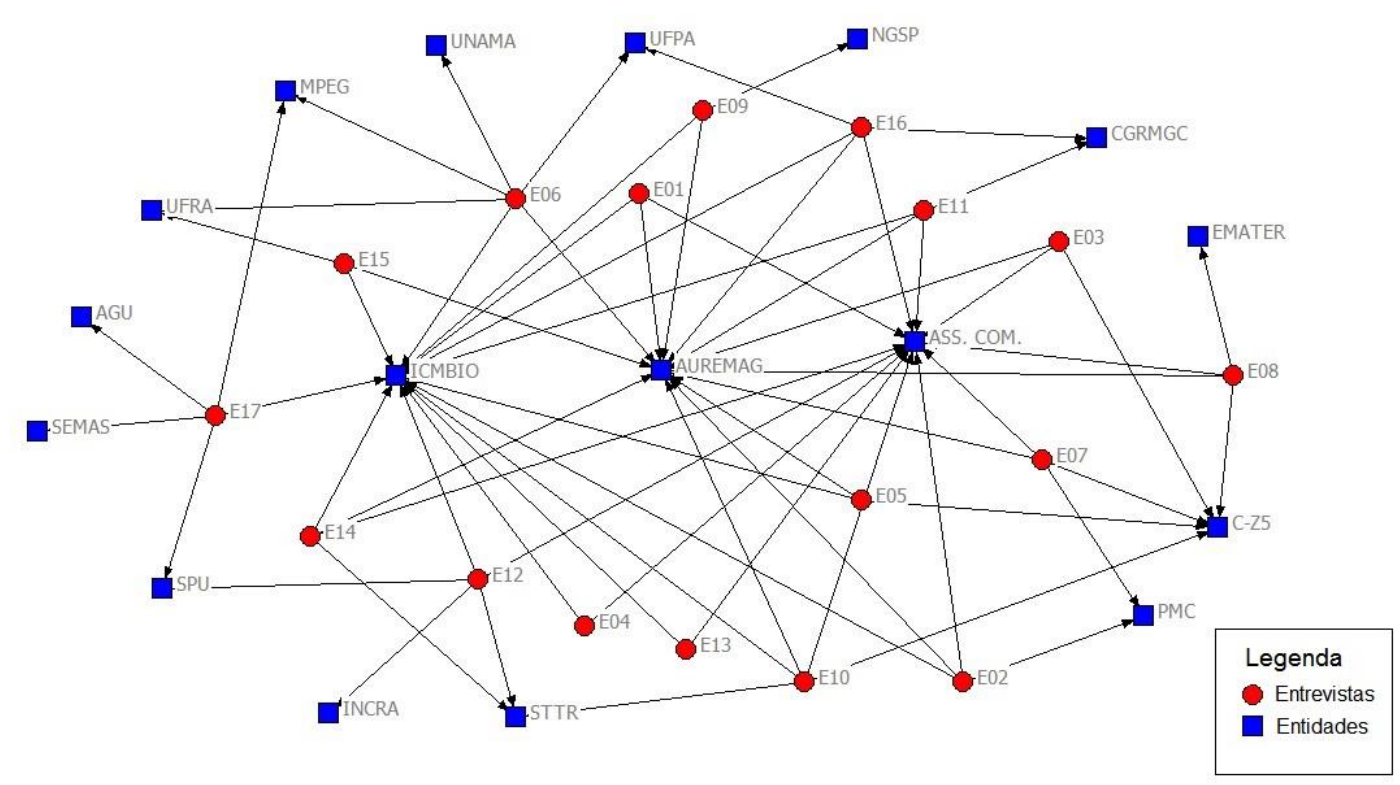

Fonte: Trabalho de campo, 2016.

A rede demonstra centralidade em apenas três entidades. O baixo nível de diálogo entre as demais expressa a fragilidade nas relações entre os membros que compõem o conselho gestor. Na verdade, a situação identificada expressa assimetria nas relações entre os membros e torna as relações interinstitucionais frágeis e com baixo aproveitamento do potencial institucional existente na composição do conselho e que poderiam, pela experiência acumulada, contribuir para a minimização dos conflitos socioambientais e de problemas pertinentes à gestão compartilhada do território no interior da RESEX.

Por outro lado, identificou-se baixa articulação entre as lideranças locais, o que, consequentemente, reduz a expressão dos grupos representados por tais lideranças. Embora as associações comunitárias apareçam como a terceira mais citadas em função do seu agrupamento, elas pouco conversam entre si e com os demais membros da rede, sobretudo de fora da esfera municipal. Assim sendo, a centralidade das informações, orientações e decisões dentro do conselho deliberativo são articuladas fundamentalmente pelo ICMBIO e pela AUREMAG, fragilizando a gestão compartilhada.

Identificou-se, então, que os debates no conselho gestor da RESEX ficam fortemente centrados nos sujeitos que exercem hegemonia no ambiente institucional: de um lado, o ICMBIO, que responde permanentemente pela presidência do conselho; e, de outro lado, a AUREMAG, que lidera e representa as comunidades do interior da reserva. Há fraca sinergia entre os membros do Conselho e esta condição, enfraquece o processo de democratização institucional e reflete sobre o uso e produção democrática dos territórios no interior da RESEX.

Os problemas mais destacados pelos entrevistados da RESEX são relativos ao uso dos recursos naturais e à gestão do território, questionando a própria 
instituição da UC, uma vez que o território abrigo foi transformado em RESEX, levando a um enquadramento de normas impeditivas à livre exploração dos recursos como se tinha antes. Por outro lado, a diferença de empoderamento e a grande assimetria entre os sujeitos compromete a participação e produz sérias distorções para a gestão democrática, e neste sentido a gestão social do território encontra barreiras e limites.

Na RESEX Mestre Lucindo, dentre os conflitos analisados, ganharam destaque aqueles relacionados à falta de informação. Entendemos que esse conflito é mais latente em função de ter sido a RESEX efetivada recentemente. $\mathrm{Na}$ análise da rede, os dados da rede demonstram precária relação entre os representantes dos polos que compõem o quadro gestor juntamente com a Associação dos Usuários da Reserva Mestre Lucindo (AUREMLUC) e o ICMBIO. No momento da execução da primeira etapa da pesquisa, o conselho Gestor da unidade ainda não havia tomado posse. Um novo levantamento foi realizado após a posse do conselho quando então foi possível a construção do gráfico, representado pela figura 3.

Figura 3 - Rede de relações entre os conselheiros para diálogo e soluções de conflitos socioambientais - RESEX Mestre Lucindo

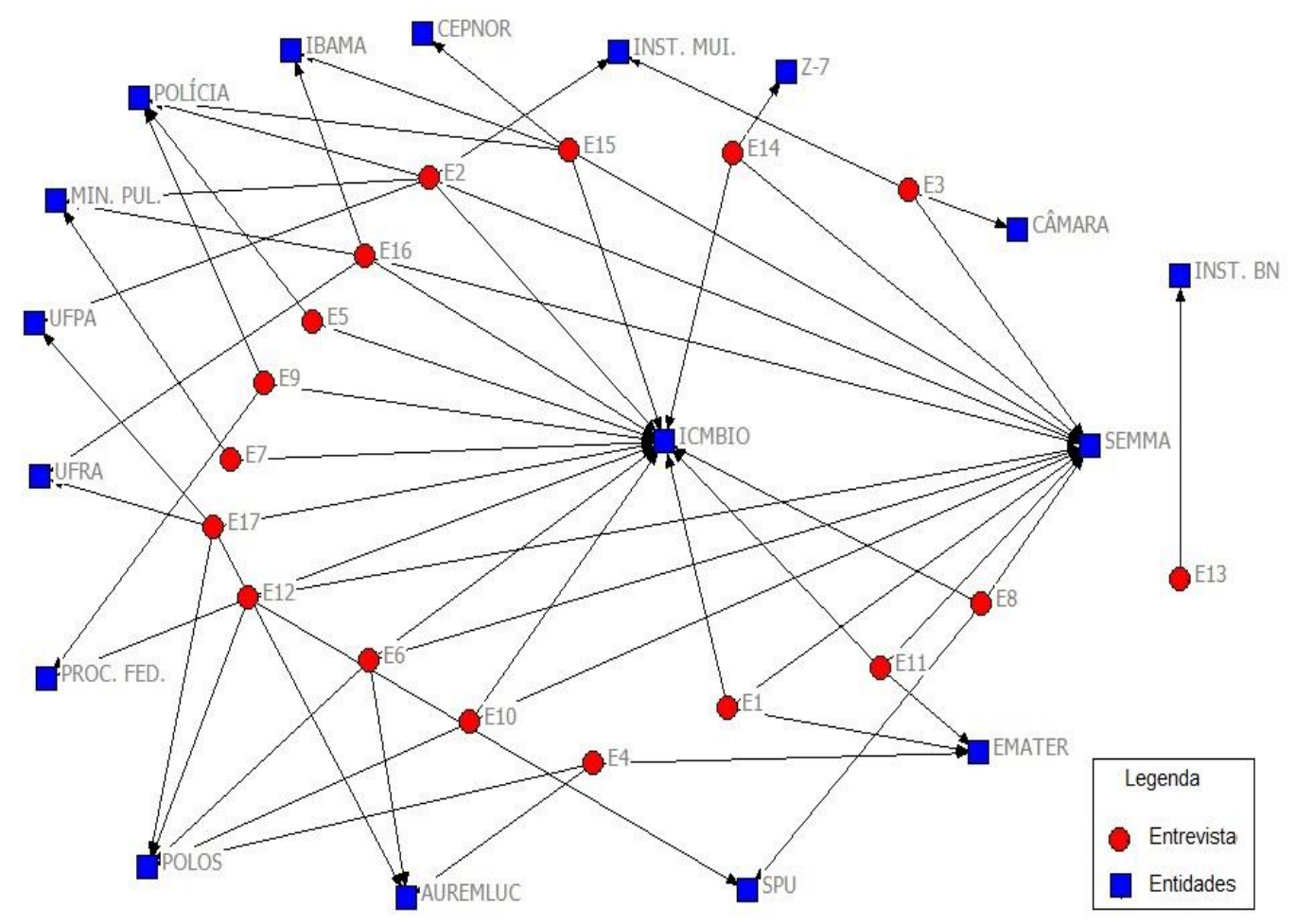

Fonte: Trabalho de campo, 2018.

Ao analisarmos a rede, verificamos que a centralidade está em duas entidades: o Instituto Chico Mendes de Conservação da Biodiversidade (ICMBIO) e a Secretaria Municipal de Meio Ambiente e Sustentabilidade (SEMMAS). As demais entidades apresentam média e baixa citação, inclusive a Associação dos Usuários da Reserva Extrativista Marinha Mestre Lucindo (AUREMLUC) e as demais organizações de nível local. De fato, o gráfico demonstra baixo grau de sinergia 
entre as entidades que compõem o conselho gestor, evidenciando fragilidade institucional desse importante instrumento de gestão compartilhada no território da RESEX. Ainda que o conselho tenha sido recém instalado, já destacamos a necessidade de seu fortalecimento para que se possa prover a gestão territorial de forma mais eficiente, democrática e capaz de amenizar os conflitos socioambientais já existentes ou que virão a emergir.

O principal conflito existente na RESEX Mestre Lucindo está relacionado à pesca e ao uso dos mangues na catação de caranguejo e preservação das matas ciliares. Embora esses problemas sejam reconhecidos por todos os entrevistados, não se verificou tentativas de diálogos e cooperação dos representantes do conselho e das comunidades e polos com instituições vinculadas a questões da pesca e catação de caranguejo. Desta forma, verifica-se que há diagnóstico dos conflitos, mas não há perspectiva de solução, por falta de interação entre os sujeitos envolvidos na gestão da RESEX. Nas entrevistas houve, inclusive, falas dos representantes de polos que as entidades não se relacionam com nenhuma instituição quando se trata de um conflito socioambiental envolvendo a RESEX, o que leva a compreender o relativo isolamento do conselho gestor. Entendemos que a falta de interesse em buscar informações e interações com instituições que, inclusive fazem parte do conselho, a exemplo das universidades federais e IBAMA dificultam o encontro de soluções para os problemas e conflitos enfrentados, demonstrando baixo nível de gestão social. Como apresentado na segunda seção deste artigo, um dos princípios da gestão social é a dialogicidade.

Na APA Algodoal-Maiandeua os conflitos socioambientais se manifestam em diferentes ordens, particularmente porque a UC já está organizada há bastante tempo. Dentro do seu processo organizativo, o uso do território para fins turísticos é o mais relevante. Em consequência, parte dos conflitos socioambientais mais proeminentes e se vinculam ao turismo e presença de visitantes e moradores de segunda residência nas ilhas. As construções irregulares e a grande quantidade de resíduos sólidos, sobretudo plásticos, resultante da dinâmica turística (e também da dinâmica da maré) foram os conflitos socioambientais mais citados pelos entrevistados. Questões relacionadas à fragilidade educacional, inclusive de educação ambiental, e de informações sobre o significado de UC e APA para os moradores da ilha também foram apresentadas.

Todavia, em função da própria experiência de gestão da UC, outros conflitos socioambientais foram citados e que merecem ser refletidos, sobretudo porque afetam fortemente a unidade de ação e gestão da APA. Dentre esses está a regularização fundiária, uma vez que ainda não há uma estrutura legal que a possibilite. A APA está localizada em nível municipal, a gestão está sob a égide estadual e as áreas costeiras são de responsabilidade da união. Trata-se de um conflito de ordem jurídico-institucional que requer articulações do conselho gestor que vá além da gestão intra UC. Questões relacionadas ao desmatamento e ocupação irregular das bordas do mangue também são da esfera federal e que fogem do escopo direto do conselho gestor. Há ainda apontamentos sobre extração de areia e rochas das praias, interferindo na dinâmica das águas e facilitando o processo de erosão, o que coloca em risco as residências localizadas na orla. 
Conflitos relacionados sob a abordagem pescadores versus pescadores também foi citado; todavia, particularmente por sujeitos representantes desse segmento produtivo. Os conflitos se dão entre pescadores de currais (demarcação de território e controle da despesca) e pescadores de dentro (da própria APA e do município) e pescadores de fora, que são aqueles que vêm de outros estados da federação.

Não obstante, por meio do gráfico-rede, identificou-se baixa articulação entre os conselheiros e entre as entidades locais, o que causa uma expressiva dependência do poder público, representado fundamentalmente pelo o Instituto de Desenvolvimento Florestal e da Biodiversidade (IDEFLOR), órgão gestor das UC em nível estadual. Esta é uma condição que fragiliza a gestão compartilhada da APA Algodoal-Maiandeua.

Figura 4 - Rede de relações entre os conselheiros para diálogo e soluções de conflitos socioambientais - APA Algodoal Maiandeua

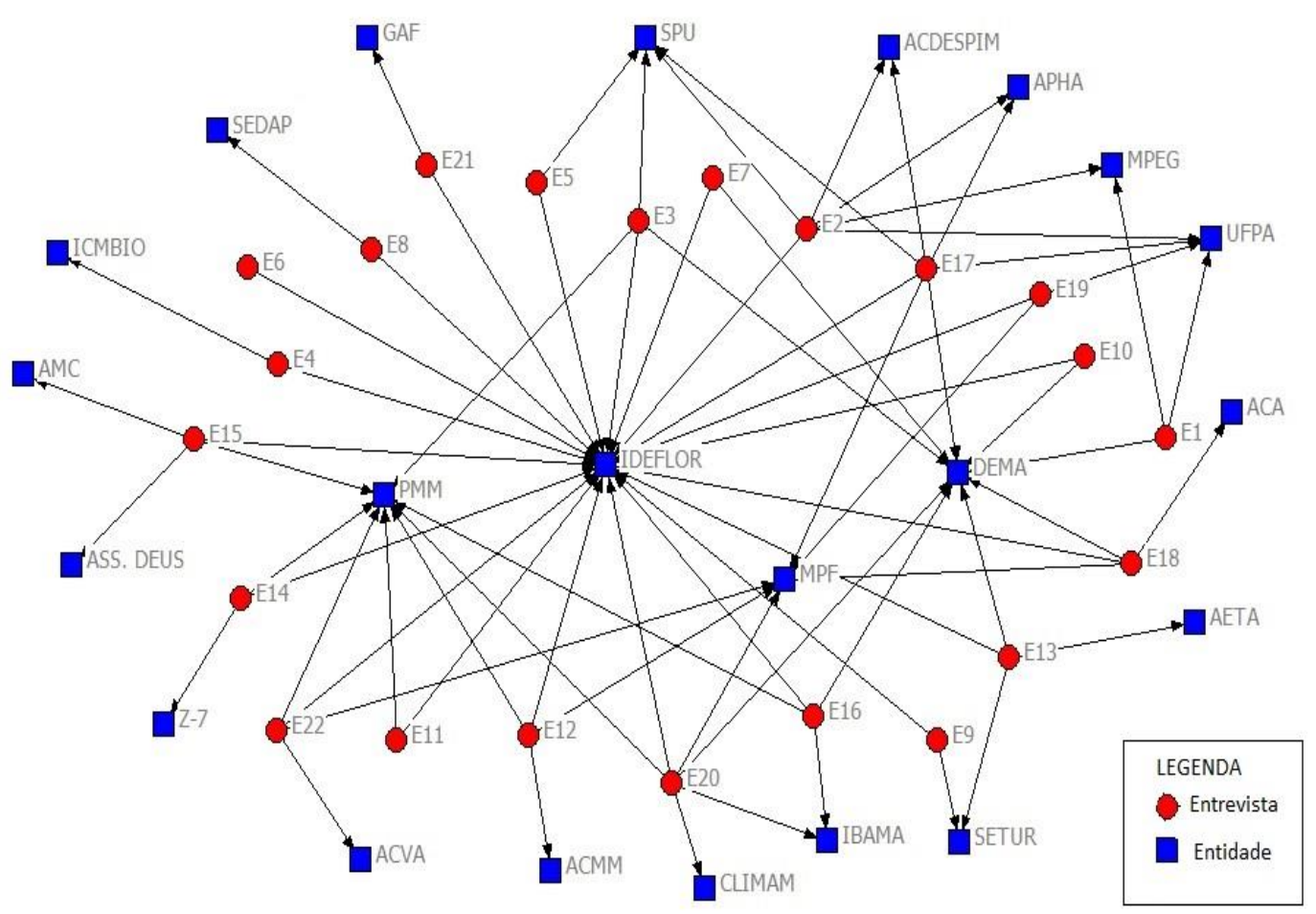

Fonte: Trabalho de campo, 2018.

Conforme o gráfico-rede, IDEFLOR detém a principal centralidade das relações no conselho gestor da APA. Entretanto, há duas outras sub-centralidades ou nós na rede que são lideradas pela Delegacia do Meio Ambiente (DEMA), órgão de caráter estadual, Prefeitura Municipal de Maracanã (PMM) e o Ministério Público Federal (MPF).

Destacamos que, ainda que tenha sido menos citadas, outras entidades foram de alguma forma reconhecidas ou lembradas como possiblidades de serem acessadas para solução de conflitos socioambientais, tais como a Universidade 
Federal do Pará (UFPA), Secretaria de Patrimônio da União (SPU) e Associação Comunitária de Desenvolvimento e Preservação da Ilha de Maiandeua (ACDESPIM). De toda ordem, todas as demais organizações foram citadas pelo menos uma vez por um dos entrevistados.

O campo teórico de gestão social assenta à sociedade o protagonismo nos processos de tomada de decisão. Entretanto, as 3 UC pesquisadas demonstram que a centralidade dos processos decisórios está primordialmente nas mãos de organizações do Estado, embora a composição dos conselhos gestores, enquanto esferas públicas para tomada de decisão (CANÇADO; PEREIRA; TENÓRIO, 2015), demonstrem inclusão, pluralismo, igualdade participativa, autonomia em prol do bem comum, conforme sugere Tenório (2007). Há de se destacar, todavia, que os conselhos gestores são espaços (esferas) públicos emergidos no âmbito do que chamamos de instituitional centred-approach.

Observações durante as reuniões dos conselhos gestores demonstraram que os diálogos e debates se dão mais comumente entre os órgãos do poder público federal e estadual, principalmente na APA Algodoal-Maiandeua e RESEX Mestre Lucindo. De certa forma, isso demonstrou baixa capacidade de diálogo das lideranças locais. De fato, identificou-se que é comum a dificuldade de aproximação e falta de diálogo dos movimentos sociais com os representantes poder público para discussão da gestão compartilhada, fato bastante evidenciado na RESEX Mãe Grande de Curuçá. Por vezes, o fato das UC terem sido criadas por regramentos legais e institucionais, afastados do entendimento da gestão social centrada na sociedade, faz com que os sujeitos envolvidos não se sintam parte do projeto, dificultando sua atuação na tomada de decisão. Isto demonstra a dificuldade de efetivação da gestão social dentro do institutional-centred approach. A ausência de interesse das instâncias governamentais em tornar mais efetiva a gestão social pode levar com que a gestão compartilhada se restrinja ao cumprimento formal das exigências legais. Destacamos, porém, que essa observação não pode ser generalizada uma vez que encontramos na APA Algodoal-Maiandeua o representante institucional do IDEFLOR-Bio muito interessado em criar mecanismos de empoderamento dos representantes das comunidades das UC, fortalecendo as possibilidades de gestão social centrada na sociedade (society-centred approach). Como dizem Schommer e Boullosa (2011), a gestão social é não somente uma concepção teórica, mas é uma prática que se exerce no dia-a-dia.

A gestão compartilhada no contexto da gestão social enquanto um modus operandi de gestão do território envolve, dentre outras características, a participação, o diálogo e a tomada de decisão coletiva. Para tal, há necessidade do interesse bem compreendido entre os atores do território de modo que se possa ter o entendimento do conflito como motor das transformações positivas nos territórios. Isso sugere o compartilhamento de informação e a melhor distribuição do poder, o que poderia ser caracterizado pela constituição de redes de relações horizontais e com mais sub-centralidades. Dentro dos casos estudados, somente a APA Algodoal-Maiandeua tem avançado nesse sentido. Os entrevistados reconheceram uma maior amplitude e diversidade de conflitos socioambientais. Este fato pode ser interpretado pelo maior tempo de existência dessa UC que, por consequência, possui maior experiência no processo de gestão compartilhada. 
Uma das características postuladas pela gestão compartilhada no âmbito da gestão social é a atuação ativa dos conselheiros, uma vez que eles representam os interesses dos grupos do qual fazem parte. Contudo, identificamos nas entrevistas que parte dos conselheiros desconhecem suas atribuições, responsabilidades e funções e, que durante as reuniões dos conselhos, participam (ou subscrevem as reuniões) mas se envolvem nos debates e no processo de na gestão. Limitam-se ao voto e por vezes não levam os anseios de seus representados às reuniões ou mesmo aos gestores públicos e/ou não fazem o caminho inverso; ou seja, não levam as informações aos seus representados.

Há alguns conflitos não são passiveis de serem radicalmente solucionados, mas sim mediados, pois fazem parte do cotidiano dos grupos sociais. O exemplo mais característico que entendemos na pesquisa de campo é o caso dos conflitos entre pescadores. Esses conflitos, embora possam ser discutidos no âmbito dos conselhos gestores, esses requerem mudanças em comportamentos sociais que vão além das representações organizacionais. Há conflitos, porém, que dependem das articulações entre os membros dos conselhos entre si e entre os conselhos e os órgãos de Estado, sejam reguladores ou gestores. Nesse caso, podemos exemplificar os conflitos de ordem de regularização fundiária, educação ambiental e fiscalização.

\section{Considerações finais}

Ao longo dos anos as Amazônias foram palco de disputa entre colonizadores e fonte de exploração de recursos naturais sem qualquer compensação, quer pela sangria irresponsável de suas reservas naturais, quer pela exploração da população que lá residia. Por mais de um século não houve preocupação com o desenvolvimento da região e melhoria das condições de vida de sua população.

A partir da compreensão mundial acerca da necessidade de proteção ambiental, com destaque para os riscos da exploração desmedida de importante fonte de recursos naturais, foram criadas, em âmbito nacional, as chamadas Unidades de Conservação. Essas foram criadas assumindo o princípio da participação social como forma de gestão. De forma particular, foi determinada pela lei do SNUC que regulamentou a criação de UC a necessidade de gestão compartilhada dos territórios. Com efeito, a gestão compartilhada deve ser realizada por agentes do Estado, representantes da sociedade civil e comunidades locais, dentro de espaços (esferas) públicas de gestão, precisamente os conselhos gestores. E, para tal, um instrumento fundamental instituído pelos regramentos das UC é o plano de gestão.

O principal objetivo do presente artigo foi analisar a emergência de conflitos socioambientais e os limites da gestão compartilhada na zona costeira do estado do Pará. Os objetos de análise foram os conselhos gestores e os respectivos planos de manejo de 3 (três) Unidades de Conservação. A partir deles buscou-se identificar os conflitos socioambientais mais proeminentes e as formas de mediação ou superação dos mesmos a partir do modelo de gestão compartilhada. Buscamos entender os limites e possibilidades da gestão compartilhada.

A pesquisa identificou 4 (quatro) categorias de conflitos: (1) aqueles relacionados a empreendimentos econômicos, (2) conflitos relacionados à 
degradação do ambiente e dos recursos naturais, (3) conflitos originados nas práticas econômicas e ocupacionais e (4) aqueles resultantes das implicações legais e sociais.

A primeira categoria se relaciona aos conflitos que podem causar impactos na estrutura física da UC e no modo tradicional de se viver no local em função da construção de empreendimentos infraestruturais e econômicos. Tem-se como exemplos a construção de portos de diferentes portes na RESEX Mãe Grande de Curuçá e hotéis e pousadas na APA Algodoal Maiandeua. A segunda categoria se refere aos conflitos originados da forma como os recursos naturais são explorados e os resíduos são descartados. Tem-se como exemplos, em todas as UC pesquisadas, desmatamento, queimadas e exploração madeireira. A terceira categoria é caracterizada por atividades realizadas por para ganhos econômicos e/ou reprodução social das comunidades locais e usuários das UC que acabam por degradar irreversivelmente o meio ambiente. Os exemplos identificados nas 3 (três) UC foram a sobrepesca e a catação de caranguejos nos períodos de defeso. Identificamos, ainda, as construções irregulares, especificamente na APA Algodoal Maiandeua. A quarta categoria de conflitos são resultantes de questões de ordem legais e institucionais que, por natureza, devem ser mediados ou solucionados fora do âmbito dos conselhos gestores, embora esse devam atuar como mediadores e representantes das demandas dos usuários da UC. Como exemplos temos a falta de regularização fundiária, a ausência de fiscalização dos crimes ambientais, tais como desmatamentos e queimadas, indefinição de competências entre órgãos governamentais (municipal, estadual e federal) e baixo fluxo de informações entre os órgãos governamentais e comunidades locais, sobretudo referente aos regramentos necessários às UC.

As diferentes categorias e tipos de conflito demonstram a complexidade que os conselhos gestores enfrentam no processo de gestão compartilhada. Se, por um lado, há o reconhecimento dos conflitos existentes por parte dos conselheiros; por outro lado, a pesquisa identificou que os conselhos, a despeito de suas configurações que assumem o princípio da participação social, pouco tem avançado na mediação ou solução dos mesmos. Isso se dá por 3 razões básicas. A primeira se refere a concentração nas organizações governamentais as lideranças dos conselhos. Nas 3 (três) UC estudadas, identificamos que os agentes do estado comandam as reuniões dos conselhos, direcionam suas pautas e os representantes da sociedade civil e comunidades locais pouco discutem ou dialogam com os mesmos. Se um dos princípios da tomada de decisão coletiva é o diálogo, esse ainda precisa ser fundamentalmente melhorado. A segunda, se refere ao fluxo de informações. Observamos que nem todos os representantes dos conselhos tem pleno conhecimento das informações necessárias para as discussões e decisões. Ora porque as informações não chegam até todos, ora porque a concentração em órgãos estatais faz com que o fluxo de informação se potencialize entre os mesmos. $\mathrm{E}$, terceiro, os conflitos relacionados a questões legais e institucionais fogem do âmbito de tomada de decisão dos próprios conselhos, embora esses devam atuar como mediador para suas soluções. Adicionalmente, conflitos de ordem econômica e infraestruturais são difíceis de serem controlados no âmbito dos conselhos, havendo necessidade, portanto, de intervenções de órgãos reguladores e legislativos, a exemplo do Ministério Público. Há, ainda, limitação por parte dos 
conselhos quando os conflitos são de natureza cultural e de reprodução econômica e social pelas práticas de trabalho utilizadas pelas comunidades locais e usuárias das UC. As mudanças de comportamento dependem fundamentalmente de suporte de políticas públicas de apoio financeiro em conjunto com políticas de educação ambiental.

De toda ordem, a gestão compartilhada continua tendo o potencial de tomada de decisão coletiva. Os próprios planos de manejo foram construídos a partir de diagnósticos participativos e traçados objetivos comuns para gestão das UC que, em alguns casos precisam de acordo de gestão, mas em outros casos são passiveis de serem implementados. Por outro lado, a conformação dos conselhos criou bases de representações institucionais que os mesmos podem recorrer para obter apoio para soluções e mediações dos conflitos. Esses são os casos das universidades, Ministério Público, Procuradoria Federal, Secretaria de Patrimônio da União, dentre outros. Entretanto, o que a pesquisa identificou é que os conselhos ainda pouco recorrem a esses órgãos em busca de apoio para soluções dos problemas estruturais na gestão da UC. As redes de relações estabelecidas são pouco utilizadas para soluções de questões de ordem socioambiental. A APA Algodoal Maiandeua é a UC que mais se relaciona e dialoga com órgãos de nível estadual e federal. A RESEX Mãe Grande de Curuçá tem avançado nessa direção, mas em suas reuniões ainda prevalecem discussões mais acaloradas e dificuldades de estabelecimento de consensos mínimos para determinados tipos de conflitos. A RESEX Mestre Lucindo ainda é muito nova e seu conselho gestor ainda está em fase de entendimento de seu próprio funcionamento.

Entendemos, então, a gestão compartilhada tem limitações, entretanto é, até então, o melhor modelo para gestão de UC. Gestão compartilhada não assume o pressuposto de superação de todos os conflitos que venham a emergir, mas é um modelo capaz de promover o reconhecimento dos conflitos existentes e apresentação de possibilidades de mediação e construção de consensos mínimos que possam ser respeitados por todos àqueles que compõem as UC. Na verdade, os conflitos são inerentes à sociedade e são propulsores de desenvolvimento territorial, todavia nem todos eles são passiveis de superação, mas com certeza são capazes de serem mediados a partir da gestão compartilhada.

Compreendemos que a gestão compartilhada é processo e prática e que vai se potencializando na medida em que os conselheiros e os próprios conselhos vão ganhando experiência e promovendo cada vez mais o diálogo e o interesse bem compreendido a partir da participação social, promovendo, assim, a democracia na gestão territorial.

\section{REFERÊNCIAS}

ARMITAGE, D.; BERKES, F.; DOUBLEDAY, N. Moving beyond Co-management. In: ARMITAGE, D.; BERKES, F.; DOUBLEDAY, N. (Org). Adaptative co-management: collaboration, learning, and multi-level governance. Toronto e Vancouver: UBC Press, 2007. 
BRASIL. Lei n. 9.985, DE 18 de julho de 2000. Regulamenta o art. 225, § 10, incisos I, II, III e VII da Constituição Federal, institui o Sistema Nacional de Unidades de Conservação da Natureza e dá outras providências., Brasília, 18 de julho de 2000; 1790 da Independência e 1120 da República, 2000.

CANÇADO, Airton Cardoso. PEREIRA, José Roberto. TENÓRIO, Fernando Guilherme. Gestão social: epistemologia de um paradigma. 2 ed. Curitiba/PR: CRV, 2015.

CANTO, Otávio do. Mineração na Amazônia: assimetria, território e conflito socioambiental. Belém: NUMA/UFPA, 2016.

CANTO, Otávio do.; ALMEIDA, Jalcione. Meio Ambiente: determinismos, metamorfoses e relação sociedade-natureza. Revista de Estudos Paraenses. Belém: IDESP, 2008.

CANTO, Otávio do.; VASCONCELLOS SOBRINHO, M.; VASCONCELLOS, A. M. A.; NOVAES, T.; ABREU, A.; SOARES, D. A. S. "Conflitos socioambientais e gestão do território em unidades de conservação da zona costeira do estado do ParáAmazônia-Brasil”. In: SILVA, C. N.; OLIVEIRA NETO, A. C.; SOBREIRO FILHO, J. (Org.). Perspectivas e análises do espaço geográfico: dinâmicas ambientais e uso dos recursos naturais. Belém: GAPTA-UFPA, 2018 p. 87-114

CANTO, Otávio do.; VASCONCELLOS SOBRINHO. M.; VASCONCELLOS. A.; ABREU. A.; MENEZES. J.; REBELO. C. Uso de rede na análise de conflito socioambiental e gestão do território na Reserva Extrativista Mãe Grande de Curuçá/PA. In: SILVA, C. N.; LIMA, R. A. P.; SILVA, J. M. P. Territórios, ordenamentos e representações na Amazônia. Belém: GAPTA/UFPA, 2017, p. 341-356.

CARLSSON, L. BERKES, F. Co-management across levels of organization: concepts and methotodological implications: Chiang Mai: Thailand, 2003.

FERREIRA, Ynis C. S. M. L.; VASCONCELLOS SOBRINHO. Cogestão e sustentabilidade em propriedade comunal na Amazônia Paraense: o caso da Resex Terra Grande do Pracuuba (PA). In: VASCONCELLOS SOBRINHO, M.; VASCONCELLOS, A. M. A. (org). Ações Públicas, Redes de cooperação e desenvolvimento local: experiências e aprendizados de gestão social na Amazônia. Belém: Unama, 2016.

FURTADO, L. G. Dinâmicas sociais e conflitos da pesca na Amazônia. In: ACSELRAD, Henri. Conflitos ambientais no Brasil (org.), Relume Dumará: Fundação Heinrich Böll, Rio de Janeiro, p. 57-71, 2004.

HERCULANO, S. Lá como cá: conflito, injustiça ambiental. I Seminário cearense contra o racismo ambiental, Fortaleza, 2006.

HONDA, Yohane Figueira. Área de proteção ambiental da ilha de Algodoal: conflitos socioambientais e perspectivas de governança. Dissertação de Mestrado. Belém: NUMA/UFPA, 2018. 
LE TOURNEAU, F.M. CANTO, Otávio do. (Org.). Amazônias brasileiras: situações locais e evoluções. Belém: NUMA/UFPA, 2019. v. I e II.

LITTLE, P. E. Territórios sociais e povos tradicionais no Brasil: por uma antropologia da territorialidade. Brasília: UNB: Série Antropologia, 2002.

LOBATO, Crisomar (Coord.). Secretaria Executiva de Ciência, Tecnologia e Meio AmbienteSECTAM. Plano de Desenvolvimento Ecoturístico da Área de Proteção Ambiental de Algodoal Maiandeua. Belém, 1999. 99p.

LOUREIRO, C. F.; AZAZIEL, M.; FRANCA, N. Educação ambiental e gestão participativa em unidades de conservação. Rio de Janeiro: Ibase/lbama, 2003.

MACKE, J. A Pesquisa-ação como estratégia de pesquisa participativa. In.: GODOI, C. K.; BANDEIRA-DE-MELLO, R.; SILVA, A. B. Pesquisa Qualitativa em Estudos Organizacionais: paradigmas, estratégias e métodos. São Paulo: Saraiva, 2006. p. 207-240.

MASCARENHAS, A. L. S; VIDAL, M. R; SILVA, E. V. O uso do SIG para definição de aspectos geomorfológicos: curso do rio Tocantins parte oriental da bacia amazônica. Revista GeoAmazônia, Belém, v. 02, n. 2, p. 68 - 78, jul./dez. 2013.

MENDONÇA, F., TALBOT, V. Participação social na gestão de unidades de conservação: uma leitura sobre a contribuição do Instituto Chico Mendes. Revista Biodiversidade Brasileira 1, 2014.

SCHOMMER, P. BOULLOSA, R. F. (Org). Gestão social como caminho para redefinição da esfera pública: Florianópolis: UDESC, 2011.

TENÓRIO, Fernando. Gestão social: metodologia e casos $5^{a}$. Ed. Rio de Janeiro: Editora FGV, 2007.

THIOLLENT, M. Metodologia da Pesquisa-Ação. 11a. ed. São Paulo: Cortez, 2002.

VASCONCELLOS SOBRINHO, M. et al. Gestão Social \& Território: práticas participativas para desenvolvimento territorial. Belém: Unama, 2018.

Otávio do Canto. Doutor. Universidade Federal do Pará. Professor Titular. UFPA, Núcleo de Meio Ambiente, Rua Augusto Corrêa 01, Guamá, Belém, Pará. E-mail docanto@ufpa.br

Mário Vasconcellos Sobrinho. Doutor. Universidade Federal do Pará e Universidade da Amazônia. Professor Titular. UFPA, Núcleo de Meio Ambiente, Rua Augusto Corrêa 01, Guamá, Belém, Pará. E-mail mariovasc@ufpa.br; mario.vasconcellos@unama.br 
Ana Maria de A. Vasconcellos. Doutora. Universidade da Amazônia. Professora Titular. UNAMA, Avenida Alcindo Cacela 261, Umarizal, Belém, Pará. E-mail anamaria.vasconcellos@unama.br

Luciana Rodrigues Ferreira. Doutora. Universidade da Amazônia. Coordenadora do Mestrado Profissional em Gestão de Conhecimentos para o Desenvolvimento Socioambiental. Av. Nazaré, 491 - Apto. 1702, Nazaré, Belém, Pará. E-mail: luciana.ferreirar@unama.br.

Ana lalis Baretta. Mestranda. Universidade Federal do Pará. UFPA, Núcleo de Meio Ambiente, Programa de Pós-graduação em Gestão dos Recursos Naturais e Desenvolvimento Local na Amazônia (PPGEDAM), Rua Augusto Corrêa 01, Guamá, Belém, Pará. E-mail: mariovasc25@gmail.com

Como citar: CANTO, Otávio do et al. Conflitos socioambientais e limites da gestão compartilhada em Unidade de Conservação na zona costeira amazônica. Redes (St. Cruz Sul, Online), Santa Cruz do Sul, v. 25, p. 1528-1552, out. 2020. ISSN 19826745doi:https://doi.org/10.17058/redes.v25i0.15239.

\section{CONTRIBUIÇÃO DE CADA AUTOR}

Otávio do Canto

Fundamentação teórico-conceitual e problematização; pesquisa de dados e análise; elaboração e redação do texto

Mário Vasconcellos Sobrinho

Fundamentação teórico-conceitual e problematização; pesquisa de dados e análise; elaboração e redação do texto

Ana Maria de A. Vasconcellos

Discussão Metodológica; elaboração, redação e revisão do texto sobre gestão social

Luciana Rodrigues Ferreira

Elaboração, redação e revisão do texto sobre gestão social; formatação e normalização.

Ana lalis Baretta

Levantamento de dados de campo; elaboração de figuras e tabelas

Fontes de financiamento: CAPES. 